\title{
The Countermeasures for Practical Teaching of Chinese International Education Major
}

\author{
Yan Hui \\ Weinan Normal University, Weinan, Shanxi, 714000
}

Keywords: Chinese International Education Major, Practice Teaching, Personnel Training, Problem Analysis

\begin{abstract}
The rise of "Chinese fever" in the world has made Chinese international education one of the hottest subjects in applied undergraduate colleges. Because teachers are important factors influencing their development in the process of international promotion of Chinese, Chinese international education professionals are required to cultivate qualified teachers. The cultivation of international talents in Chinese should highlight the characteristics of applicability, complexness and internationalization, and attach importance to the development of students' social practice ability, intercultural communication ability and international vision. Therefore, practice teaching plays a prominent role in this major. However, in practical teaching, there are still many problems. The paper analyzes the problems and puts forward specific strategies for solving them so as to improve the quality of Chinese international education professionals.
\end{abstract}

\section{The Problems in the Practical Teaching of Chinese International Education}

Specifically, the practical teaching of Chinese international education also has the following problems:

\subsection{Curriculum design issues}

Courses covered by the Chinese International Education Major include a wide range of subjects, including literary, linguistic, cultural and pedagogical teaching, etc. However, each course is not professionally integrated and permeated with a lack of pertinence and professionalism melt, just loosely integrate these professional [1]. Students are lack of systematic learning in the process, and the teaching emphasis on theoretical knowledge, which leads to students extensive but professional learning. And some students do not even understand the basic concepts of Chinese language, making professional education into a universal general education. It can not reflect the professional characteristics of the major and is not much benefit for the professional ability of students. However, the existing internship practice of Chinese major in international education has gone abroad [2]. The spatial separation of internship place and theoretical study place leads to the separation of theoretical study and professional practice from each other, which is not conducive to improving students' ability to apply knowledge.

\subsection{Teaching management issues}

In the aspect of teaching management, there is a problem of emphasis on theory, light practice, heavy talent and light knowledge in Chinese international education. Theory and practice are complementary relations. Theory guides practice and practice guides theory. To improve the teaching abilities of Chinese international education majors, teacher should teach students not only theoretical knowledge but also more practical opportunities to complete theoretical understanding and internalization [3]. However, at present, most of the major courses in Chinese international education are theoritical courses, such as language, writing, culture, etc., which have not only fewer internships but also fewer actual cases in the process of explaining the theory. Even though there are international students in each school, smaller Chinese students have less chance of getting in touch with international students. Students can only gain indirect experience of Chinese teaching methods and techniques from their lecturers and can not really understand the teaching rules [4]. However, 
most of the practical courses offered by the Chinese international education major are cultural surveys and language surveys. Before the training, the teachers will guide them. However, there are few supervisors and guides in the practice so that practical results can not be guaranteed. The content is scattered and there is no resultant force to improve teaching ability. Another point is that the cost of internship abroad is relatively high. Some students may not have the opportunity to go abroad for practical training and may only practice independently. In addition, students who are majoring in Chinese international education should not only possess strong theoretical knowledge, but also possess Chinese cultural skills such as paper cutting, calligraphy and Tai Chi, so as to spread Chinese culture. Many Chinese students are more interested in learning art and culture, which mislead their students that the teaching of Chinese as a foreign language focusing on the dissemination of culture after they go abroad, and ignore the teaching of Chinese characters.

\subsection{Problems in the construction of teaching staff}

At present, the Chinese international education major in our country is a relatively new specialty. Most of the teachers engaged in Chinese international education major are Chinese language and literature or related majors. Although some courses are proposed in the talent training program, there are many problems in the actual commencement of classes, especially for teachers [5]. Chinese international education is an independent and marginalized humanities and social sciences, but it also has prominent interdisciplinary features related to education, culture, foreign language and literature, communication, psychology, international relations and so on [6]. The construction of teaching staff in Chinese international education should not be limited to Chinese departments or liberal arts colleges. Instead, teachers should be integrated in the entire school. And as a new discipline, many teachers engaged in teaching Chinese as a second language do not have the practical experience of teaching in other countries. Some teachers do not even have contact with foreign students. They do not understand the real situation of teaching Chinese as a foreign language and cannot reach the professional level of guidance students', thus restricting the improvement of students' practical ability.

\section{The Construction Principles of Chinese International Education Practice Teaching System}

Specifically, it is necessary to follow the principles of systematicness, gradualism and practicality in constructing the practical teaching system of Chinese international education major. First of all, the practical teaching system for Chinese major in international education must be systematic. All teaching and learning contents are closely interlinked and complementary. All the teaching activities in this major are centered on cultivating students' innovative spirit and practical application ability, and building a complete practice teaching system. And adjust courses according to the practice of teaching links to gradually enhance students' practical ability [7]. Break the scattered problems in the past practice teaching and strengthen the study of the basic knowledge of Chinese, Chinese and Western cultures, the second foreign language and teaching skills. Lay a solid foundation of theoretical knowledge and form a complete practical teaching system. Second, abide by the principle of gradualness. Chinese international education bachelor total has four school years, and the construction of practical teaching system should follow the principle of gradual and orderly. The freshman focus on Chinese writing, language expression and other basic ability. Sophomore make foreign students language learning survey combined with cultural courses, and conduct multi-cultural investigation. In the third year, the major is to improve students' ability of communication and writing through teaching activities of Chinese as a foreign language course. In the third year, students try their best to write small essays. In the fourth year, they practice teaching internships in domestic students' class and write graduation thesis. The whole process not only reflects the continuity, but also takes into account the development, both including in-class teaching practice, extra-curricular practice, etc., which continue to improve students' practical ability. The principle of practice is the basic principle of constructing the practice teaching system of Chinese international education. The cultivation of Chinese-speaking international education professionals focuses on improving students' ability of intercultural communication, teaching of Chinese in 
international education and training applied talents. Therefore, it is necessary to arrange practice classes. Courses provide good practice opportunities for students. Such as compare the differences between Chinese and foreign knowledge in classroom teaching to help students strengthen their memory and deepen their understanding. For another example, in order to distinguish "modern Chinese" courses from the knowledge of Chinese major, emphasis should be placed on teaching Chinese as a foreign language practice content, to reflect the professional Chinese teaching practice of international education content.

\section{The Construction Strategy of Chinese International Education Practice Curriculum System}

In view of the problems existing in the practical teaching of Chinese international education, it is suggested that the existing practical teaching system should be improved from the following aspects:

\subsection{Clear positioning of the discipline}

Chinese international education is a new interdisciplinary and highly integrated emerging frontier subject with the comprehensive attributes of multiple disciplines. However, Chinese international education professionals not only have to undertake the tasks of teaching Chinese, but also assume the responsibility of promoting Chinese culture. Different from those of the major of Chinese as a foreign language, the Chinese international education requires the cultivation of compound talents. The compound mainly refers to the structure of students' knowledge, their knowledge of Chinese theory, cultural knowledge, foreign language and cultural knowledge, linguistic ontology theory and language teaching practice, etc. However, the practical characteristics of Chinese international education also determine that students must have the ability to translate theoretical knowledge into vocational skills [8]. Chinese language teaching skills are one of the core skills. Through the study of Chinese major in international education, students should have the ability to work with teacher that teach Chinese as a foreign language and the ability of communicating Chinese and foreign cultures. They should not only engage in teaching Chinese at all kinds of educational units both at home and abroad, but also be able to work in foreign trade institutions, enterprises, institutions and functional departments engaged in related word processing, cultural exchange and related language work. This shows that the Chinese international education major is not based on the study of the Chinese language ontology but emphasizes the practical work related to Chinese language and culture.

\subsection{Strengthen the practice of students' cultural skills}

On the one hand, we should set up practical courses of cultural skills. It is necessary to put the assessment of students' cultural skills training into professional training programs, set special credits and incorporate cultural practice courses into professional elective courses. Cultural practice courses include Chinese knitting, paper-cutting, Taijiquan, calligraphy and other types of Chinese culture and art. Various cultural groups, such as Beijing Opera, traditional Chinese painting, folk art, cooking and so on, are set up in the school. Students choose to participate according to their own interests and hobbies, and use the results of the group works as the evaluation content of the cultural practice course. School can also set up eloquence, social etiquette, debate skills and other courses, and such courses can improve students' communicative competence and adaptability. On the other hand, various cultural activities can be carried out [9]. Encourage students to use the time to go out of school to enter the community for short-term cultural experience, such as the study of local culture, visit the museum of history, visit historical and cultural monuments, etc. Enable students to better understand Chinese culture and use cultural skills to learn knowledge to pay practice, and experience different cultural activities. Colleges can make cultural activities with local cultural departments and publicity departments. Students try to popularize the cultural knowledge of community residents, and truly learn to apply. 


\subsection{Strengthen the practice of students' comprehensive skills}

On the one hand, divide the practice direction. Schools divide the courses in the internship phase of students according to the actual needs of students and local needs, and internship direction can be divided into educational internships, enterprises internships and other internships. Students choose according to their own interests. Such as, if students choose educational internships, they can enter the school for internship. If they choose enterprises internship, students may contact the foreign affairs agencies and other agencies for foreign secretarial and foreign management internship. If they choose other units of internship, students can also be involved in foreign tourism and cultural transmission internship in other industries. Teachers should do a good job tracking management of student internships to ensure internship results. On the other hand, research activities should be carried out. Extracurricular hours should be used to select suitable research topics based on professional perspectives. Students may be grouped together or grouped by teachers to form social practice groups to conduct field research and write research reports. Compared with classroom practice, research practice can promote students' problem awareness and innovation awareness, and truly realize the organic combination of theory and practice.

\section{Conclusions}

In short, in the face of the increasingly severe employment pressure of the Chinese international education major, we must do the basic work of cultivating professional talents in the undergraduate stage. And we also should think about the sustainable development of disciplines behind the major. The professional practice teaching system has an extremely important role in the entire professional personnel training mode. Chinese international education must meet the needs of the society and the market, seize the opportunities, implement a more targeted and practical training program for qualified personnel, identify and orientate them and develop distinctive features. So we can seek more long-term development for the Chinese international education, transport more talents and make a modest contribution to the Chinese international promotion in our school.

\section{Acknowledgements}

Scientific research project financed by the Education Department of Shaanxi Provincial Government: Research on the Training Path of International Chinese Education Professionals in Shaanxi Universities under "One Belt and One Road" Strategy (17JK0264)

\section{References}

[1] Jin Qianwen. Consideration on the Time of Practical Teaching in International Education Major in Chinese [J]. Henan Science and Technology, 2015 (12): 253-254

[2] SUN Zhi-wei. College journalism professional practice teaching problems and countermeasures [J]. Educational Exploration, 2015 (8): 41-42

[3] CAO Bao-ping. Teaching of Chinese as a Second Foreign Language Major. Modern Chinese [J], $2011(10)$

[4] Wang Bin. Reflections on Constructing Practical Teaching Mode of Chinese as a Foreign Language. Journal of Huaibei Normal University [J], 2012 (10): 184-186

[5] Li Wei. Reflections on the curriculum of majoring in Chinese as a foreign language. Journal of Hubei Institute of Economics [J], 2015 (7): 179-180

[6] Cui Xiliang.English language teaching and the development and prospect of Chinese international education [J].

[7] Li Yi. Chinese international promotion and the development of our country's international education [J]. Journal of Xi'an International Studies University, 2015 (12): 51-53 
[8] Journal of Dali University, 2010 (11): 71-73 [8] ZHANG Ru-Mei. Multi-Mode Exploration of Practical Teaching for Majoring in Chinese as a Foreign Language - A Case Study of Dali University [J]

[9] WU Ying-hui. Research on the Construction of International Chinese Teaching Discipline and International Communication in Chinese [J]. Journal of Linguistic Writing, 2010 (8): 35-42 